\title{
The utility of a novel colonoscope with retroflexion for colorectal endoscopic submucosal dissection
}

\section{다 (1) $\odot$}

\author{
Authors \\ Institutions \\ 1 Department of Endoscopy, Hiroshima University \\ Hospital, Hiroshima, Japan \\ 2 Department of Gastroenterology and Metabolism, \\ Hiroshima University Hospital, Hiroshima, Japan
}

Hidenori Tanaka', Shiro Oka², Shinji Tanaka', Katsuaki Inagaki², Yuki Okamoto ${ }^{2}$, Kenta Matsumoto², Kazuki Boda², Ken Yamashita², Kyoku Sumimoto², Yuki Ninomiya', Nana Hayashi' ${ }^{1}$, Kazuaki Chayama²

submitted 19.9.2018

accepted after revision 21.11.2018

Bibliography

DOI https://doi.org/10.1055/a-0810-0567 |

Endoscopy International Open 2019; 07: E130-E137

(c) Georg Thieme Verlag KG Stuttgart · New York ISSN 2364-3722

Corresponding author:

Shiro Oka, Department of Gastroenterology and

Metabolism, Hiroshima University Hospital, 1-2-3, Kasumi, Minamiku, Hiroshima 734-8551, Japan

Fax: +81-82-257-5939

oka4683@hiroshima-u.ac.jp

\section{ABSTRACT}

Background and study aims The PCF-H290TI/L produced by Olympus is a novel colonoscope equipped with some advantageous features for endoscopic treatment. It is expected to improve the potential for retroflexion and overall endoscope operability, which can reduce the difficulty of performing colorectal ESD. The aim of this study was to evaluate the utility of the novel colonoscope in colorectal ESD.

Methods Three hundred and forty-eight consecutive colorectal lesions resected via ESD between June 2014 and January 2017 at Hiroshima University Hospital were included in the retroflexion ability analysis. We compared the retroflexion potential of PCF-H290TI to that of a conventional endoscope. Two hundred and twenty-seven colorectal lesions located in the left-sided colon and resected with ESD between April 2009 and February 2018 were enrolled in the treatment outcome analysis. Treatment outcomes using PCF-H290TI compared to those of the conventional colonoscope, and outcomes of the PCF-H290TI with retroflexion compared to those of the conventional colonoscope without retroflexion were evaluated by propensity score matching.

Results The retroflexion rate with the PCF-H290TI was $76 \%$, which was significantly higher than the $44 \%$ rate with the conventional scope. Endoscope operability was better and dissection speed was faster when using the PCFH290TI with retroflexion compared to the conventional colonoscope without retroflexion. There were no significant differences between the groups in en bloc resection rate and adverse events.

Conclusion Compared to the conventional colonoscope, the PCF-H290TI/L made it easier to perform ESD via a retrograde approach regardless of tumor location, and thus may be useful for performing colorectal ESD.

\section{Introduction}

Improvements in colonoscopes and development of new devices have made colorectal endoscopic submucosal dissection (ESD) safer and more reliable as a minimally invasive treatment option for managing colorectal tumors [1-11]. Accumulation of experience and technical progress by endoscopists have also improved performance of colorectal ESD [12-17]. However, colorectal ESD is not as easy to perform as gastric ESD $[15,18,19]$, and we previously reported that poor endoscope operability was one of the predictors of incomplete resection and perforation in colorectal ESD [20].

A novel colonoscope, the PCF-H290TI/L (Olympus Medical Systems Co., Tokyo, Japan) was released for use in Japan in March 2018. It is a "therapeutic colonoscope," which was developed as a refinement of conventional colonoscopes, and is equipped with some advantageous features for endoscopic colorectal treatment, especially for ESD. The PCF-H290TI/L is expected to improve retroflexion ability and endoscope operability, which can reduce the difficulty of performing colorectal ESD. 
980 lesions with indication of ESD between april 2009 and february 2018

107 lesions resected by hybrid ESD were excluded

646 lesions located in the right-sided colon and rectum were excluded

227 lesions resected by ESD in the left-sided colon

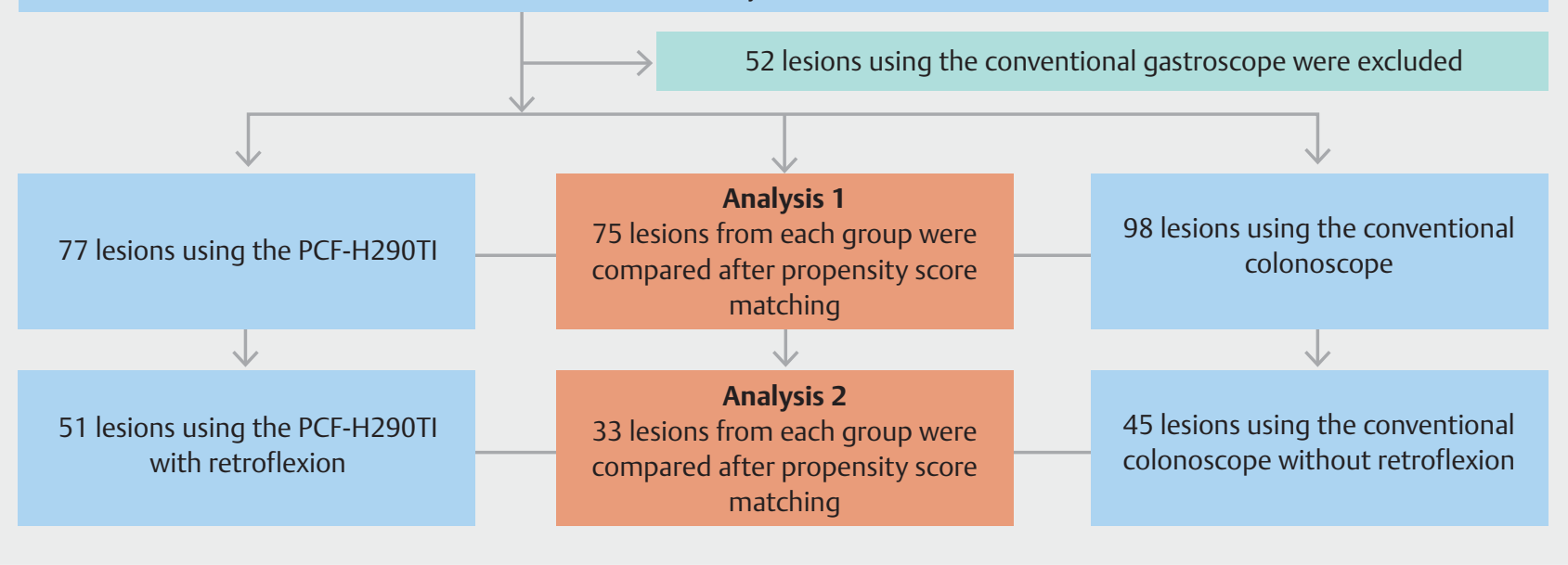

- Fig. 1 Flowchart of the treatment outcome analysis.

The retroflexion technique is performed by making " $\mathrm{U}$ turns" with the bending section of the endoscope. The utility of the retroflexion technique was previously reported for polyp detection [21,22], polypectomy [21,23], endoscopic mucosal resection (EMR) [24], and ESD [25]. Therefore, ease of retroflexion with the novel colonoscope may also be useful for colorectal ESD.

The aim of this study was to evaluate the utility of the novel colonoscope in performing colorectal ESD.

\section{Patients and methods}

This was a retrospective single-center study comprising two evaluation components: a retroflexion ability analysis and a treatment outcome analysis. To evaluate the difference in retroflexion ability of the novel colonoscope versus the conventional endoscope, 348 consecutive colorectal lesions resected via ESD at Hiroshima University Hospital, Japan, between June 2014 and January 2017 were included in the retroflexion ability analysis. The evaluating colonoscopies were performed using conventional colonoscopes in all cases on a day preceding the actual treatment. The lesions were evaluated according to the indication for ESD, retroflexion ability, and endoscope operability. Retroflexion was attempted during ESD for all lesions except those at the cecum, and the retroflexion success rates using the novel colonoscope and the conventional endoscope were evaluated. Retroflexion was attempted up to three times during the evaluating colonoscopy and that performed for ESD. It was defined as retroflexion improvement that retroflexion was not possible using the conventional colonoscope on the evaluating colonoscopy, became possible using the PCFH290TI for ESD.

Next, 980 consecutive colorectal lesions resected via ESD between April 2009 and February 2018 at our institution were enrolled in the treatment outcome analysis ( $\triangleright$ Fig. 1 ). Lesions located in the left-sided colon, including both the descending and sigmoid colons, were included. Lesions that were resected using the hybrid ESD method $[1,26]$ (in which a snare was used after circumferential incision), that were located in the right-sided colon (cecum, ascending colon, and transverse colon) and rectum, and that were treated using a gastroscope were excluded. Among the remaining 175 lesions, there were 77 lesions in the group treated using the PCF-H290TI and 98 lesions in the group treated using a conventional colonoscope. Thereafter, propensity score matching was conducted with a 1:1 ratio according to growth type and tumor size to reduce selection bias. Ultimately, there were 75 lesions from each group, and treatment outcomes related to ESD were evaluated (Analysis 1). Moreover, outcomes related to ESD for the 33 cases using the PCF-H290TI with retroflexion and the conventional colonoscope without retroflexion were evaluated after propensity score matching was conducted in the same manner (Analysis 2). In the treatment outcome analysis, the following items were evaluated: retroflexion rate, endoscope operability, degree of submucosal fibrosis, procedure time, dissection speed, en bloc resection rate, histological complete resection rate, postoperative bleeding, and intraoperative perforation rate. Poor endoscope operability was defined by occurrences of paradoxical endoscope movement, poor control with adhesions, and passive movement of the lesion or the endoscope resulting from 
the patient's respirations or heartbeats [20]. Good and intermediate scope operability were defined by the performance of detailed and smooth maneuvers upon direct transmission of hand operation, and maneuvers that were not completely smooth, but caused no hindrance to operation, respectively. Degree of submucosal fibrosis was classified as none, mild, or severe as previously reported [27]. Specimen area $\left(\mathrm{mm}^{2}\right)$ was calculated as:

long diameter $(\mathrm{mm}) \times$ short diameter $(\mathrm{mm}) \times 0.25 \times 3.14$

Dissection speed $\left(\mathrm{mm}^{2} / \mathrm{min}\right)$ was calculated as:

area $\left(\mathrm{mm}^{2}\right)$ /procedure time $(\mathrm{min})$

Postoperative bleeding was defined as any apparent bleeding, massive melena, or $>2 \mathrm{~g} / \mathrm{dL}$ decrease in hemoglobin concentration compared to the preoperative level [28].

This study was conducted in accordance with the Declaration of Helsinki. Written informed consent was obtained from all the enrolled patients. This study protocol was approved by Hiroshima University's Institutional Review Board.

\section{Indications for ESD}

Indications for ESD were based on the guidelines published by the Japan Gastroenterological Endoscopy Society [29] and the Japanese Society of Gastroenterology [30] and included: lesions for which en bloc resection with snare EMR was difficult to perform, including laterally spreading tumors of the nongranular type (LST-NG), tumors with type $V_{\text {I }}$ pit patterns, shallow invasive submucosal carcinomas, large depressed-type tumors, and large protruding-type tumors suspected of containing carcinoma; mucosal tumors with submucosal fibrosis; sporadic localized tumors associated with chronic bowel inflammation such as ulcerative colitis; local residual or recurrent tumors that developed after endoscopic resection.

\section{ESD procedure}

ESDs were performed by two endoscopic experts (SO and ST) in all cases. A standard tip hood (Olympus), ST hood (FUJIFILM, Japan) or its short-type (FUJIFILM) was attached to the tip of the endoscope as appropriate in each case. A 50/50 mixture of $0.4 \%$ sodium hyaluronate (Muco Up; Boston Scientific, Japan) and $10 \%$ glycerin solution was added to a small amount of indigo carmine, which was initially injected into the submucosa. Next, a circumferential incision was made, and submucosal dissection was performed. The Dual Knife (Olympus) or Dual Knife J (Olympus) were used as cutting devices at the onset of the procedure. In specific situations, such as with cases of severe submucosal fibrosis, other knives, including the ITknife nano (Olympus) or SB Knife Jr (Sumitomo Bakelite, Japan) were additionally used.

All specimens were fixed in $10 \%$ formalin buffer, sliced into 2-mm widths, and examined under a microscope. Histological complete resection was defined as pathologically identified en bloc resection with negative horizontal and vertical margins.

\section{Scope selection}

In the retroflexion ability analysis, the CF-H260AZI, PCFQ260AZI, or CF-HQ290I (Olympus) was used in the latest evaluating colonoscopy. PCF-Y0062 is the prototype of the novel
PCF-H290TI colonoscope. As our institution had only one, it was impossible to use it for all cases during the study period, considering that there were so many treatments being performed simultaneously, and the scope required adequate cleaning time. Therefore, the PCF-Y0062 was preferentially used on lesions for which some difficulties were anticipated, such as poor endoscope operability identified during the evaluating colonoscopy. A conventional gastroscope, GIF-Q260], GIF-H260Z, or GIF-H260 (Olympus), was used for some lesions located in the sigmoid colon and rectum that required retroflexion, and a conventional colonoscope, PCF-Q260AZI, or CFH260AZI (Olympus), was used for the other lesions.

In the treatment outcome analysis, the conventional colonoscopes included the PCF-Y0021 (prototype, Olympus), PCFY0047 (prototype, Olympus), PCF-Q260AZI, CF-H260AZI, and PCF-Q260JI (Olympus).

\section{PCF-H290TI/L}

The PCF-H290T series has two subtypes of different lengths, the PCF-H290TI and the PCF-H290TL, with working lengths of $1,330 \mathrm{~mm}$ and $1,680 \mathrm{~mm}$, respectively. Each has the following characteristics: a thinner distal end outer diameter of $9.8 \mathrm{~mm}$, equivalent to some gastroscopes; small tip turning ability, due to a shortened length of the distal end and the bending section; angulation ranges of the bending section of $210^{\circ}$ upward, $180^{\circ}$ downward, and $160^{\circ}$ left and right; variable stiffness, by which the hardness of the insertion tube could be adjusted; high force transmission function, by which the torque at hand could be well transmitted to the distal end of the scope; a 3.2-mm forceps channel diameter; water jet function; and high-definition imaging. These features made it possible to perform detailed and smooth maneuvers during the endoscopic treatments, especially during ESD.

\section{Statistical analysis}

JMP version 14.0 (SAS institute Inc., Cary, North Carolina, United States) was used for the statistical analysis. Continuous variables were analyzed using the Student's t-test and MannWhitney $U$ test, and qualitative variables were analyzed using Pearson's chi-square test and Fischer's exact test. A $P$ value $<0.05$ was considered statistically significant.

\section{Results}

\section{Retroflexion ability analysis}

One hundred and fifty-four lesions were resected during ESD using the PCF-H290TI (PCF-H290TI group) and the other 194 were resected using the conventional endoscope (the conventional scope group). Retroflexion was attempted during ESD in all cases, and the retroflexion rate was evaluated in this analysis. The conventional scope group included eight cases in which the gastroscope was used in the sigmoid colon and 23 cases in which it was used in the rectum. The total and location-specific retroflexion rates using the PCF-H290TI and the conventional scope are shown in $>$ Table 1 . Retroflexion was performed in $76 \%$ of the cases (117/154) using the PCF-H290TI, which was significantly higher than the $44 \%$ of cases $(86 / 194)$ using the 
- Table 1 Retroflexion rates using the PCF-H290TI versus the conventional scope.

\begin{tabular}{|c|c|c|c|c|}
\hline \multirow[t]{2}{*}{ Location } & \multirow[t]{2}{*}{ PCF-H290TI } & \multicolumn{2}{|c|}{ Conventional scope } & \multirow[t]{2}{*}{$P$ value } \\
\hline & & Colonoscope & Gastroscope & \\
\hline Total & $117 / 154(76)$ & \multicolumn{2}{|l|}{$86 / 194(44)$} & $<.0001$ \\
\hline Cecum, $n=50$ & $0 / 8(0)$ & $2 / 42(5)$ & - & .398 \\
\hline Ascending colon, $n=130$ & $14 / 18(78)$ & $32 / 62(52)$ & - & .042 \\
\hline Transverse colon, $\mathrm{n}=71$ & $32 / 38(84)$ & $15 / 33(46)$ & - & $<.001$ \\
\hline Descending colon, $\mathrm{n}=13$ & $6 / 7(86)$ & $4 / 6(67)$ & - & .415 \\
\hline Sigmoid colon, $n=60$ & $32 / 42(76)$ & $2 / 10(20)$ & $6 / 8(75)$ & $\begin{array}{l}<.001^{1} \\
.943^{2}\end{array}$ \\
\hline Rectum, $n=74$ & $33 / 41(80)$ & $5 / 10(50)$ & $20 / 23(87)$ & $\begin{array}{l}.059^{1} \\
.503^{2}\end{array}$ \\
\hline
\end{tabular}

conventional scope. When examined according to tumor location, the retroflexion rate with the PCF-H290TI was significantly higher than that with the conventional scope in the ascending and transverse colons. In the sigmoid colon, the PCF-H290TI was able to be retroflexed significantly more often than the conventional colonoscope, at a rate equivalent to that of the conventional gastroscope. Similarly, the retroflexion rate with the PCF-H290TI in the rectum was as high as that of the conventional gastroscope. Lesions located in the descending colon were relatively few, and retroflexion was unnecessary for lesions located in the cecum. In the PCF-H290TI group, although the retroflexion rate was only $34 \%(53 / 154)$ using the conventional colonoscope on the evaluating colonoscopy, it was improved to $76 \%$ (117/154) when using the PCF-H290TI during ESD ( $\triangleright$ Fig. 2). The retroflexion improvement rate was $63 \%$ $(64 / 101)$ altogether, approximately $60 \%$ to $90 \%$ from the ascending to the sigmoid colon, and $50 \%$ in the rectum ( $\triangleright$ Table 2).

\section{Outcome of ESD in the left-sided colon using the PCF-H290TI and the conventional colonoscope}

- Table 3 shows the results of Analysis 1, which includes outcomes related to ESD in the left-sided colon using the PCF$\mathrm{H} 290 \mathrm{TI}$ and the conventional colonoscope after propensity score matching. There were no significant differences between the two groups in treatment outcomes including procedure time, dissection speed, en bloc resection rate, histological complete resection rate, and adverse events.

\section{Outcome of ESD in the left-sided colon using the PCF-H290TI with retroflexion, and the conventional colonoscope without retroflexion}

Because the retroflexion rate was higher in the PCF-H290TI group, we evaluated treatment outcomes between the PCFH290TI with retroflexion and the conventional colonoscope without retroflexion (Analysis 2). There was a significant difference in endoscope operability between the two groups, and

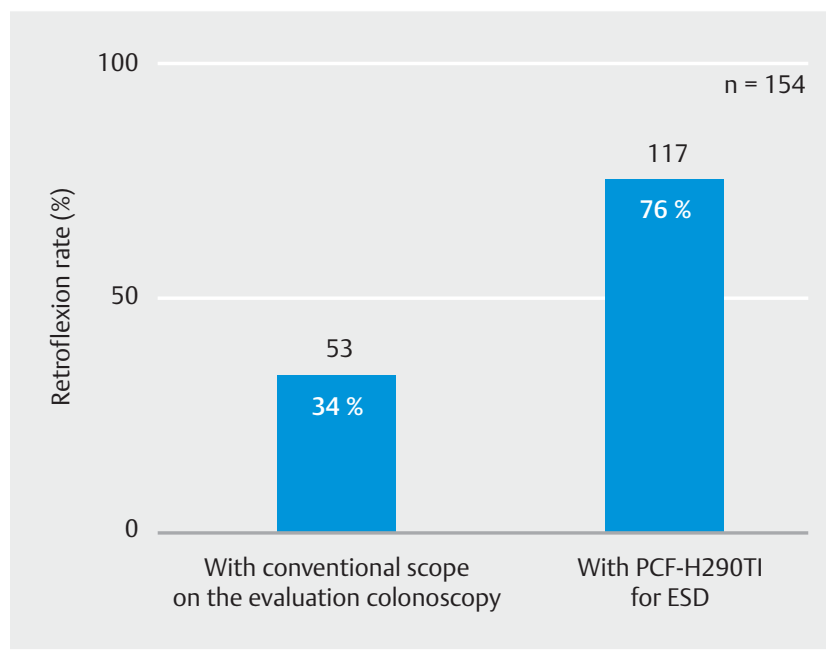

- Fig. 2 Changes in the retroflexion rate when using the PCFH290TI. Although the retroflexion rate was only $34 \%$ (53/154) with the conventional colonoscope on the evaluating colonoscopy, the rate improved to $76 \%(117 / 154)$ with the PCF-H290TI during ESD.

there were more cases with good endoscope operability in the PCF-H290TI group compared to the conventional colonoscope group ( $\vee$ Table 4). Dissection speed was significantly faster in cases wherein the PCF-H290TI with retroflexion was used compared to those in which the conventional colonoscope without retroflexion was used. En bloc resection and histological complete resection rates were $100 \%(33 / 33)$ and $94 \%(31 / 33)$, respectively, for the PCF-H290TI with retroflexion, and $97 \%$ $(32 / 33)$ and $94 \%(31 / 33)$, respectively, for the conventional colonoscope without retroflexion. There were no significant differences between the two groups. In addition, no significant differences were found between the two groups in incidence of AEs including postoperative bleeding and intraoperative perforation. 
- Table 2 Retroflexion improvement using the PCF-H290TI.

\begin{tabular}{|c|c|c|c|}
\hline \multirow[t]{2}{*}{ Location } & \multicolumn{2}{|c|}{ Retroflexion ability } & \multirow[t]{2}{*}{ Retroflexion improvement ${ }^{1}$} \\
\hline & $\begin{array}{l}\text { PCF-H290TI } \\
\text { for ESD }\end{array}$ & $\begin{array}{l}\text { Conventional scope on } \\
\text { evaluating colonoscopy }\end{array}$ & \\
\hline Total, n-154 & $117(76)$ & $53(34)$ & $64 / 101(63)$ \\
\hline Cecum, $n=8$ & $0(0)$ & $0(0)$ & - \\
\hline Ascending colon, $\mathrm{n}=18$ & $14(78)$ & $6(33)$ & $8 / 12(67)$ \\
\hline Transverse colon, $\mathrm{n}=38$ & $32(84)$ & $6(16)$ & $26 / 32(81)$ \\
\hline Descending colon, $\mathrm{n}=7$ & $6(86)$ & $0(0)$ & $6 / 7(86)$ \\
\hline Sigmoid colon, $\mathrm{n}=42$ & $32(76)$ & $16(38)$ & $16 / 26(62)$ \\
\hline Rectum, $n=41$ & $33(80)$ & $25(61)$ & $8 / 16(50)$ \\
\hline
\end{tabular}

${ }^{1}$ The cases wherein it was not possible to perform retroflexion using the conventional colonoscope, but was possible using the PCF-H290TI

- Table 3 Outcomes related to ESD in the left-sided colon using the PCF-H290TI and the conventional colonoscope after propensity score matching.

\begin{tabular}{|c|c|c|c|}
\hline Variables & $\begin{array}{l}\text { PCF-H290TI } \\
n=75\end{array}$ & $\begin{array}{l}\text { Conventional scope } \\
n=75\end{array}$ & $P$ value \\
\hline Tumor size, $\mathrm{mm}$, mean $\pm \mathrm{SD}$ & $30 \pm 15$ & $31 \pm 15$ & .637 \\
\hline Growth type & & & 1.000 \\
\hline - LST-G & $19(25)$ & $19(25)$ & \\
\hline - LST-NG & $43(57)$ & $43(57)$ & \\
\hline - Polypoid & $13(17)$ & $13(17)$ & \\
\hline Submucosal fibrosis & & & .880 \\
\hline - None & $18(24)$ & $20(27)$ & \\
\hline - Mild & $37(49)$ & $34(45)$ & \\
\hline - Severe & $20(27)$ & $21(28)$ & \\
\hline Retroflexion ability & $50(67)$ & $36(48)$ & .020 \\
\hline Endoscope operability & & & $<.0001$ \\
\hline - Good & $25(33)$ & $8(11)$ & \\
\hline - Intermediate & $17(23)$ & $42(56)$ & \\
\hline - Poor & $33(44)$ & $25(33)$ & \\
\hline Procedure time, min, mean $\pm S D$ & $80 \pm 63$ & $71 \pm 52$ & .482 \\
\hline Dissection speed, $\mathrm{mm}^{2} / \mathrm{min}$, mean $\pm \mathrm{SD}$ & $22 \pm 13$ & $21 \pm 12$ & .396 \\
\hline En bloc resection & $75(100)$ & $74(99)$ & .238 \\
\hline Histological complete resection & $71(95)$ & $73(97)$ & .400 \\
\hline Postoperative bleeding & $1(1)$ & $4(5)$ & .158 \\
\hline Intraoperative perforation & $4(5)$ & $2(3)$ & .400 \\
\hline Histology & & & .786 \\
\hline - Dysplasia & $31(41)$ & $33(44)$ & \\
\hline - Tis carcinoma & $31(41)$ & $27(36)$ & \\
\hline - T1 carcinoma & $13(17)$ & $15(20)$ & \\
\hline
\end{tabular}

LST-G, laterally spreading tumor granular type; LST-NG, laterally spreading tumor non-granular type; SD, standard deviation 
Table 4 Outcomes related to ESD in the left-sided colon using the PCF-H290TI with retroflexion and the conventional colonoscope without retroflexion after propensity score matching.

\begin{tabular}{|c|c|c|c|}
\hline Variables & $\begin{array}{l}\text { PCF-H290TI with retroflexion } \\
n=33\end{array}$ & $\begin{array}{l}\text { Conventional scope without retroflexion } \\
n=33\end{array}$ & $P$ value \\
\hline Tumor size, $\mathrm{mm}$, mean \pm SD & $27 \pm 9$ & $27 \pm 9$ & .849 \\
\hline Growth type & & & .824 \\
\hline - LST-G & $9(27)$ & $7(21)$ & \\
\hline - LST-NG & $20(61)$ & $21(64)$ & \\
\hline - Polypoid & $4(12)$ & $5(15)$ & \\
\hline Submucosal fibrosis & & & .791 \\
\hline - None & $12(36)$ & $12(36)$ & \\
\hline - Mild & $14(42)$ & $16(48)$ & \\
\hline - Severe & $7(21)$ & $5(15)$ & \\
\hline Endoscope operability & & & .012 \\
\hline - Good & $16(48)$ & $5(15)$ & \\
\hline - Intermediate & $7(21)$ & $13(39)$ & \\
\hline - Poor & $10(30)$ & $15(45)$ & \\
\hline Procedure time, min, mean $\pm S D$ & $61 \pm 31$ & $58 \pm 25$ & .964 \\
\hline Dissection speed, $\mathrm{mm}^{2} / \mathrm{min}$, mean $\pm \mathrm{SD}$ & $25 \pm 12$ & $19 \pm 13$ & .011 \\
\hline En bloc resection & $33(100)$ & $32(97)$ & .236 \\
\hline Histological complete resection & $31(94)$ & $31(94)$ & 1.00 \\
\hline Postoperative bleeding & $0(0)$ & $2(6)$ & .092 \\
\hline Intraoperative perforation & $2(6)$ & $0(0)$ & .092 \\
\hline Histology & & & .936 \\
\hline - Dysplasia & $15(45)$ & $15(45)$ & \\
\hline - Tis carcinoma & $12(36)$ & $13(39)$ & \\
\hline - T1 carcinoma & $6(18)$ & $5(15)$ & \\
\hline
\end{tabular}

\section{Discussion}

Our study revealed that the novel colonoscope, the PCFH290TI, made endoscopic retroflexion easier during ESD when compared to the conventional colonoscope, regardless of tumor location. In terms of treatment outcomes in colorectal ESD, the PCF-H290TI improved retroflexion especially in the left-sided colon, which is useful for colorectal ESD.

Retroflexion can be performed by pushing the endoscope slide along the wall of the intestine at left or right angles. Retroflexion should be attempted carefully, not forcefully, because of the potential for perforation and mucosal injury.

Using the PCF-H290TI, retroflexion was performed in approximately $80 \%$ of cases in any location for two reasons: 1 ) its thin distal end outer diameter and 2) its small tip turning at the short length of the distal end and the bending section. In the sigmoid colon, the retroflexion rate was $76 \%$ with the PCF-
H290TI, compared to just $20 \%$ with the conventional colonoscope. It was previously reported that endoscope retroflexion during colonoscopy was useful for colorectal tumor detection [22,23], polypectomy [21,23], EMR [24], and ESD [25]. The endoscope can sometimes be inadvertently moved during respirations or heartbeats, which can worsen scope operability and cause unexpected endoscope movement, thus increasing risk of AEs. Retroflexion makes it possible to stabilize the endoscope as it contacts and becomes fixed to the colon wall. This allows for treatment of lesions located on the proximal side of folds and flexures. Previously, we used the gastroscope for retroflexion at the sigmoid colon and rectum because gastroscopes were generally thinner than colonoscopes, which made it easier and safer to perform retroflexion maneuvers. In actuality, the gastroscopes were used for 52 of 227 lesions (23\%) located in the left-sided colon during this study period. However, the downward angulation range of the gastroscope is relatively 
small, and this was insufficient for injection or dissection in the downhill direction beyond folds or flexures. This problem was solved using the novel colonoscope PCF-H290TI, as its downward angulation range is sufficient at $180^{\circ}$. In addition, its small tip turning by the short length of the distal end and the bending section made it easier to approach the lesions and enter the submucosal layer during the retroflexion procedure, especially for the lesion in contact with the dentate line (data not shown).

Fujihara et al. reported that procedure time for tumors $>40 \mathrm{~mm}$ and dissection time in colorectal ESD with retroflexion were shorter and faster than those with forward views, without increasing the rate of AEs such as bleeding and perforation [25]. In this study, we evaluated the utility of the novel colonoscope, the PCF-H290TI for performing colorectal ESD, with a focus on lesions located in the left-sided colon because the lumen there is relatively twisted and narrow, making ESD technically difficult [15]. There were no significant differences in treatment outcomes related to ESD in the entire colon and the rectum between the PCF-H290TI and the conventional colonoscope (data not shown). We demonstrated that retroflexion using the PCF-H290TI made dissection speeds faster and improved endoscope operability in the left-sided colon compared to the conventional colonoscope without retroflexion. We observed these findings in spite of the fact that the PCF-H290TI was used in more cases with anticipated difficulties identified during the evaluating colonoscopy. This result was considered to be due to endoscope retroflexion and PCF-H290TI functions, such as the high force transmission function, by which detailed and smooth maneuvers can be performed. Although colorectal ESD in this study was performed by two experts, the PCFH290TI may be rather useful for beginners with limited maneuvering capability, because poor endoscope operability is one of the factors that makes colorectal ESD difficult [20].

We considered that the sole weakness of this novel colonoscope is that it bends easily, making insertion into the deep colon somewhat difficult because of its thin outer diameter. However, this problem can be overcome by adjusting the scope rigidity and combining it with the use of a single-use splinting tube (ST-CB1, Olympus) [31].

There are some limitations in this study. First, this was a nonblinded retrospective study conducted at a single institution. In addition, there was some selection bias because we used the PCF-H290TI preferentially in cases with anticipated difficulties, even though propensity score matching was performed in the treatment outcome analysis. Second, although it is possible that an attachment hood used for ESD could affect retroflexion ability, the retroflexion rate of each attachment hood could not be examined. Third, it is possible that results of the treatment outcome analysis were affected by the learning curve, as the conventional scope group included the cases performed temporally earlier than those in the PCF-H290TI group. Finally, evaluation of endoscope operability may be different between endoscopists, as it was made based on a subjective scale. Similarly, retroflexion ability is somewhat influenced by the endoscopist's skill level. Nevertheless, this study identified the utility of the PCF-H290TI for colorectal ESD, especially in cases involving the left-sided colon with retroflexion. Our findings can contribute to increasing the performance optimization of colorectal ESD.

\section{Conclusion}

In conclusion, the novel colonoscope PCF-H290TI/L made it easier to perform retroflexion in comparison with the conventional colonoscope, regardless of tumor location, which may be useful for performing colorectal ESD in the left-sided colon.

\section{Competing interests}

PCF-Y0062, a prototype scope of PCF-H290TI, was provided by Olympus. Shinji Tanaka received a lecture fee from Olympus.

References

[1] Tanaka S, Terasaki M, Kanao H et al. Current status and future perspectives of endoscopic submucosal dissection for colorectal tumors. Dig Endosc 2012; 24: 73 - 79

[2] Oka S, Tanaka S, Saito Y et al. Local recurrence after endoscopic resection for large colorectal neoplasia: a multicenter prospective study in Japan. Am J Gastroenterol 2015; 110: 697 - 707

[3] Shigita K, Oka S, Tanaka S et al. Long-term outcomes after endoscopic submucosal dissection for superficial colorectal tumors. Gastrointest Endosc 2017; 85: 546 - 553

[4] Boda K, Oka S, Tanaka S et al. Clinical outcomes of endoscopic submucosal dissection for colorectal tumors: a large multicenter retrospective study from the Hiroshima GI Endoscopy Research Group. Gastrointest Endosc 2018; 87: 714-722

[5] Asayama N, Oka S, Tanaka S et al. Long-term outcomes after treatment for T1 colorectal carcinoma. Int J Colorectal Dis 2016; 31: 571 578

[6] Tamaru Y, Oka S, Tanaka S et al. Endoscopic submucosal dissection for anorectal tumor with hemorrhoids close to the dentate line: a multicenter study of Hiroshima GI Endoscopy Study Group. Surg Endosc 2016; 30: 4425 - 4431

[7] Tamaru Y, Oka S, Tanaka S et al. Long-term outcomes after treatment for T1 colorectal carcinoma: a multicenter retrospective cohort study of Hiroshima GI Endoscopy Research Group. J Gastroenterol 2017; 52: $1169-1179$

[8] Nakamura F, Saito Y, Haruyama S et al. Short-term prospective questionnaire study of early postoperative quality of life after colorectal endoscopic submucosal dissection. Dig Dis Sci 2017; 62: 3325 - 3335

[9] Asayama N, Oka S, Tanaka S et al. Endoscopic submucosal dissection as total excisional biopsy for clinical T1 colorectal carcinoma. Digestion 2015; 91: 64-69

[10] Kim JH, Baek IH, Kim KO et al. Usefulness and feasibility of endoscopic submucosal dissection for colorectal tumor: a nationwide multicenter retrospective study in Korea. J Gastrointest Oncol 2016; 7: 924 - 930

[11] Tanaka S, Asayama N, Shigita K et al. Towards safer and appropriate application of endoscopic submucosal dissection for T1 colorectal carcinoma as total excisional biopsy: future perspectives. Dig Endosc 2015; $27: 216-222$

[12] Ohata K, Ito T, Chiba $\mathrm{H}$ et al. Effective training system in colorectal endoscopic submucosal dissection. Dig Endosc 2012; 24: 84- 89

[13] Takeuchi Y, lishi H, Tanaka S et al. Factors associated with technical difficulties and adverse events of colorectal endoscopic submucosal 
dissection: retrospective exploratory factor analysis of a multicenter prospective cohort. Int J Colorectal Dis 2014; 29: 1275-1284

[14] Saito Y, Yamada M, Abe $S$ et al. Colorectal endoscopic submucosal dissection: technical advantages compared to endoscopic mucosal resection and minimally invasive surgery. Dig Endosc 2014; 26 : 52 61

[15] Mizushima T, Kato M, Iwanaga I et al. Technical difficulty according to location, and risk factors for perforation, in endoscopic submucosal dissection of colorectal tumors. Surg Endosc 2015; 29: 133-139

[16] Imai K, Hotta K, Yamaguchi Y et al. Preoperative indicators of failure of en bloc resection or perforation in colorectal endoscopic submucosal dissection: implications for lesion stratification by technical difficulties during stepwise training. Gastrointest Endosc 2016; 83: $954-962$

[17] Kang DU, Choi Y, Lee HS et al. Endoscopic and clinical factors affecting the prognosis of colorectal endoscopic submucosal dissectionrelated perforation. Gut Liver 2016; 10: 420-428

[18] Jeon HH, Lee HS, Youn YH et al. Learning curve analysis of colorectal endoscopic submucosal dissection (ESD) for laterally spreading tumors by endoscopists experienced in gastric ESD. Surg Endosc 2016; 30: $2422-2430$

[19] Shiga H, Kuroha M, Endo K et al. Colorectal endoscopic submucosal dissection (ESD) performed by experienced endoscopists with limited experience in gastric ESD. Int J Colorectal Dis 2015; 30: 1645 - 1652

[20] Hayashi N, Tanaka S, Nishiyama S et al. Predictors of incomplete resection and perforation associated with endoscopic submucosal dissection for colorectal tumors. Gastrointest Endosc 2014; 79: 427 435

[21] Vemulapalli KC. REX DK. Retroflexion in colonoscopy: Why? Where? When? How? What value? Gastroenterology 2013; 144: 882 - 883
[22] Pishvaian AC, Al-Kawas FH. Retroflexion in the colon: a useful and safe technique in the evaluation and resection of sessile polyps during colonoscopy. Am J Gastroenterol 2006; 101: 1479-1483

[23] Rex DK, Khashab M. Colonoscopic polypectomy in retroflexion. Gastrointest Endosc 2006; 63: 144-148

[24] Liu S, Li Y, Yang H et al. Retroflexion-assisted endoscopic mucosal resection: a useful and safe method for removal of low rectal laterally spreading tumors. Surg Endosc 2016; 30: 139 - 146

[25] Fujihara S, Kobara H, Mori $\mathrm{H}$ et al. Comparison of retroflexed and forward views for colorectal endoscopic submucosal dissection. Int J Med Sci 2015; 12: $450-457$

[26] Terasaki M, Tanaka S, Oka S et al. Clinical outcomes of endoscopic submucosal dissection and endoscopic mucosal resection for laterally spreading tumors larger than $20 \mathrm{~mm}$. J Gastroenterol Hepatol 2012; 27: $734-740$

[27] Matsumoto A, Tanaka S, Oka S et al. Outcome of endoscopic submucosal dissection for colorectal tumors accompanied by fibrosis. Scand J Gastroenterol 2010; 45: 1329-1337

[28] Tajiri H, Kitano S. Complication associated with endoscopic mucosal resection: definition of bleeding that can be viewed as accidental. Dig Endosc 2004; 16: $134-136$

[29] Tanaka S, Kashida H, Saito Y et al. JGES guidelines for colorectal endoscopic submucosal dissection/endoscopic mucosal resection. Dig Endosc 2015; 27: $417-434$

[30] Tanaka S, Saito Y, Matsuda T et al. Evidence-based clinical practice guidelines for management of colorectal polyps. J Gastroenterol 2015; 50: $252-260$

[31] Asayama N, Oka S, Tanaka S et al. Clinical usefulness of a single-use splinting tube for poor endoscope operability in deep colonic endoscopic submucosal dissection. Endosc Int Open 2016; 4: E614 -E617 